Article

\title{
A New Strategy for the Synthesis of Fluorinated Polyurethane
}

\author{
Pu-Cheng Wang ${ }^{1}$, Dan Lu ${ }^{2}$, Hu Wang ${ }^{2}$ and Ru-Ke Bai ${ }^{2, *}$ \\ 1 Institute of Nuclear Physics and Chemistry, China Academy of Engineering Physics, Mianyang 621000, China \\ 2 CAS Key Laboratory of Soft Matter Chemistry, Department of Polymer Science and Engineering, \\ University of Science and Technology of China, Hefei 230026, China \\ * Correspondence: bairk@ustc.edu.cn
}

Received: 11 August 2019; Accepted: 30 August 2019; Published: 2 September 2019

check for updates

\begin{abstract}
An alternating fluorinated copolymer based on chlorotrifluoroethylene (CTFE) and butyl vinyl ether (BVE) was synthesized by RAFT/MADIX living/controlled polymerization in the presence of S-benzyl O-ethyl dithiocarbonate (BEDTC). Then, using the obtained poly(CTFE-alt-BVE) as a macro chain transfer agent (macro-CTA), a block copolymer was prepared by chain extension polymerization of vinyl acetate (VAc). After a basic methanolysis process, the poly(vinyl acetate) (PVAc) block was transferred into poly(vinyl alcohol) (PVA). Finally, a novel fluorinated polyurethane with good surface properties due to the mobility of the flexible fluorinated polymer chains linked to the network was obtained via reaction of the copolymer bearing the blocks of PVA with isophorone diisocyanate (IPDI) as a cross-linking agent.
\end{abstract}

Keywords: fluorinated polyurethane; fluorinated polymer; chlorotrifluoroethylene

\section{Introduction}

Fluorinated polyurethanes, a new class of functional materials, combine some virtues of fluorinated polymer and polyurethane, such as high thermal stability, good mechanical properties, excellent chemical resistance (to acids, alkalis, and solvents), and attractive surface properties. [1-16] As a result, they have attracted considerable interest in recent years.

Fluorocarbon chains or groups have been incorporated into polyurethanes by fluorinated chain extenders, [17-21] diisocyanates, [22] glycols, [23-41] side groups/chains [42-58], and end-cappers [59-66]. In 2005, for the first time, a novel fluorinated polyurethane based on polyurethane macromonomers partly acrylate-endcapped with hexafluorobutyl acrylate was synthesized through macromonomer radical copolymerization [17]. Synthesis of fluorinated polyurethane with fluorinated diisocyanates the less used due to the high synthesizing cost and poor variability of fluorinated diisocyanate. Takakura et al. produced a series of fluorine-containing poly(urethane-urea)s with 2,2,3,3,4,4,5,5-octafluorohexamethylene diisocyanate in 1990 [22]. Fluorinated polyurethanes synthesized with fluorinated diols as soft segments are more common. In 1992, Ho prepared a fluorinated polyurethane based on ethylene-fluoroalkyl-ethylene diol 3-(trifluoromethyl)-3,4,4,5,5,6,6,7,7,8,8-undecafluoro-1,10-decanediol and 1,6-hexamethylene diisocyanate [40]. Liu et al. prepared a series of main-chain-fluorinated thermoplastic polyurethane elastomers based on fluoropoly(oxyalkylene)diol by one-step bulk polymerization [41]. Introducing fluorinated side groups/chains is another common method for the preparation of fluorinated polyurethanes. In 1995, Chapman et al. reported the synthesis and characterization of a series of fluorinated polyurethanes with fluorinated side groups $\left(-\mathrm{CH}_{2}\left(\mathrm{CF}_{2}\right)_{n} \mathrm{CF}_{3}, \mathrm{n}=0,2,3,6\right)$ on the soft blocks [58]. Recently, Shi et al. synthesized several fluorinated polyurethanes containing fluoroether side groups on the hard segments [54]. Fluorinated polyurethanes prepared by fluorinated alcohols 
as end-cappers usually show no evident improvement in properties compared with hydrogenated polyurethanes, owing to the less fluorine content and lower molecular weight of fluorinated alcohols. Although many strategies for the synthesis of fluorinated polyurethanes have been proposed, it is still a challenge to introduce fluorinated long chains with defined length or molar mass into polyurethanes.

As we know, living/controlled radical polymerization is a powerful tool for the synthesis of well-defined polymers with predetermined molar mass, low dispersity, and various architectures [67-70]. Some successful works focusing on the living/controlled radical (co)polymerization for fluoroolefins, such as vinylidene fluoride (VDF), tetrafluoroethylene (TFE), 3,3,3-trifluoropropene (TFP), hexafluoropropylene (HFP), and chlorotrifluoroethylene (CTFE), have been done in recent years [71-81]. RAFT/MADIX polymerization initiated by $\gamma$-rays seems to be very suitable for fluoroolefins. In 2011, Liu et al. successfully achieved RAFT/MADIX copolymerization of CTFE and butyl vinyl ether (BVE) at room temperature under ${ }^{60} \mathrm{Co} \gamma$-ray irradiation with a xanthate as a mediating agent [75]. Another fluorinated copolymer, poly(HFP-alt-BVE), was prepared under similar conditions in 2013 [77]. Later in 2014, RAFT/MADIX copolymerization of CTFE and N-vinylpyrrolidone under ${ }^{60} \mathrm{Co} \gamma$-ray irradiation with S-benzyl O-ethyl dithiocarbonate (BEDTC) as the mediating agent was reported [78]. However, there is a problem that could not be ignored in the polymerization reactions irradiated by ${ }^{60} \mathrm{Co}$ $\gamma$-ray. In fact, the hyper-powerful energy of $\gamma$-rays could cause many unexpected and complicated crosslinking reactions during the polymerization process.

In this work, we firstly prepared a fluorinated copolymer (poly(CTFE-alt-BVE)) with defined molar mass and low dispersity by RAFT/MADIX copolymerization of CTFE and BVE using BEDTC as a chain transfer agent in moderate conditions without ${ }^{60} \mathrm{Co} \gamma$-rays in order to avoid the unexpected crosslinking reactions. Based on this, we successfully prepared a novel crosslinked fluorinated polyurethane with flexible fluorinated polymer chains linked to the network. As the fluorinated polymer chains can easily migrate to the surface of the matrix, the surface properties of the material were significantly improved. The whole reaction process is depicted in Scheme 1.

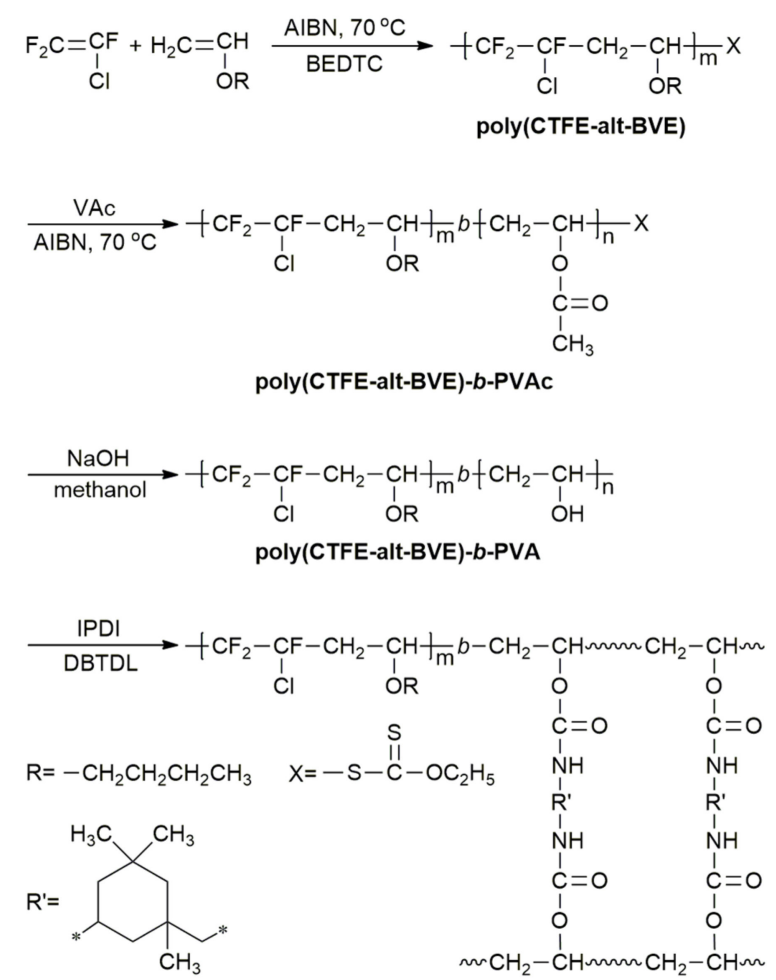

Scheme 1. Schematic representation of the synthetic procedures of fluorinated polyurethane. AIBN: azodiisobutyronitrile, BEDTC: S-benzyl O-ethyl dithiocarbonate, CTFE: chlorotrifluoroethylene, BVE: butyl vinyl ether, VAc: vinyl acetate, PVAc: poly(vinyl acetate), PVA: poly(vinyl alcohol), IPDI: isophorone diisocyanate, DBTDL: dibutyltin dilaurate. 


\section{Materials and Methods}

\subsection{Materials}

CTFE was purchased from Zhejiang Juhua Co., Ltd, Quzhou, China. BVE was obtained from Hubei Xinjing New Materials Co., Ltd, Wuhan, China, was dried with $\mathrm{CaH}_{2}$ and distilled under reduced pressure before use. VAc, ethyl acetate, methanol, tetrahydrofuran (THF), and $\mathrm{NaOH}$ were purchased from Sinopharm Chemical Reagent Co., Ltd (Shanghai, China). VAc was purified by passing through a basic alumina column, and subsequently distilled. Ethyl acetate was refluxed and distilled over $\mathrm{CaH}_{2}$. AIBN, isophorone diisocyanate (IPDI), and dibutyltin dilaurate (DBTDL) were purchased from Aladdin Industrial Corporation (Shanghai, China). AIBN was recrystallized from methanol twice before use. BEDTC was synthesized according to a previous report [82] (As shown in the Supplementary Section 1). All other chemicals were used as received unless otherwise noted.

\subsection{Characterization}

${ }^{1} \mathrm{H},{ }^{19} \mathrm{~F}$, and ${ }^{13} \mathrm{C}$ NMR spectra were recorded on a Bruker DPX-400 spectrometer (Bruker Corporation, Billerica, USA), using $\mathrm{CDCl}_{3}$ as a solvent. All NMR tests were carried out at $25^{\circ} \mathrm{C}$.

The values of the number-average molar mass $\left(M_{n}\right)$ and dispersity $\left(M_{w} / M_{n}\right)$ were determined by means of a Waters 150C gel permeation system (Waters Corporation, Milford, USA) equipped with $10^{3}$, $10^{4}$, and $10^{5} \AA$ Waters Ultrastyragel columns and a light scattering detector, using THF $\left(1.0 \mathrm{~mL} \cdot \mathrm{min}^{-1}\right)$ as the eluent at $25^{\circ} \mathrm{C}$, and the calibration was carried out with polystyrene standards.

FT-IR spectra were recorded on a Bruker VECTOR-22 infrared spectrometer (Bruker Corporation, Billerica, USA).

X-ray photoelectron spectroscopy (XPS) analysis was performed on a Thermo-VG Scientific ESCALab 250 instrument (Thermo Fisher Scientific Inc, Waltham, USA) with Al K $\alpha$ radiation as the excitation source.

Static contact angles were measured with an optical contact angle meter (Solon (Shanghai) technology science Co. Ltd.) at ambient temperature.

Thermogravimetric analysis (TGA) was performed with a DTG-60H apparatus from Shimadzu (Kyoto, Japan) at a heating rate of $10^{\circ} \mathrm{C} \cdot \mathrm{min}^{-1}$ from room temperature up to a maximum of $700{ }^{\circ} \mathrm{C}$ under nitrogen.

Chemical resistance was evaluated by spot test according to ASTM D1308. The dried coating with thickness of about $10 \mu \mathrm{m}$ was exposed to droplets of different solvents for $24 \mathrm{~h}$ at room temperature in a closed box kept in equilibrium with the solvent vapor. The droplets were then wiped, and the chemical resistance was determined by evaluating the changes in coating integrity, haze, or hardness. A visual scale was used to compare these changes: 10 (no effect), 8 (light haze), 6 (softening), 4 (cracks), 2 (heavily damaged), 0 (completely solubilized).

\subsection{Synthetic Procedures}

\subsubsection{General Procedure for RAFT/MADIX Copolymerization of CTFE and BVE}

The reaction was performed in a $30 \mathrm{~mL}$ stainless steel autoclave equipped with a manometer, a safety inlet valve, and a magnetic stirrer. First, a mixture of $5.1 \mathrm{mg}$ AIBN $(0.031 \mathrm{mmol}), 33.5 \mathrm{mg}$ BEDTC $(0.158 \mathrm{mmol}), 2.0 \mathrm{~mL} \mathrm{BVE}(15.8 \mathrm{mmol})$, and $5.0 \mathrm{~mL}$ ethyl acetate was introduced into the autoclave. Then, the vessel was closed and immersed in liquid nitrogen for $15 \mathrm{~min}$. After several nitrogen-vacuum cycles to remove any trace of oxygen, $2.5 \mathrm{~g}$ CTFE $(21 \mathrm{mmol})$ was condensed into the autoclave via a mass flow meter, and its exact amount was assessed by double weighing (weight difference before and after filling the autoclave with CTFE). The polymerization was carried out at $70{ }^{\circ} \mathrm{C}$ for a predetermined time and then quenched by cooling with ice water. The unreacted CTFE was slowly vented. The solution was concentrated and precipitated in methanol. The polymer was finally dried under vacuum at $50{ }^{\circ} \mathrm{C}$ until a constant weight was attained, and the conversion of the monomer was determined by 
gravimetry. Preparation of items for XPS, chemical resistance and static contact angle measurements: $0.2 \mathrm{~g}$ of the obtained copolymer was dissolved in $1.0 \mathrm{~mL}$ ethyl acetate, and then the solution was cast onto glass plates, followed by drying at $70^{\circ} \mathrm{C}$ for $12 \mathrm{~h}$.

\subsubsection{Synthesis of Poly(CTFE-alt-BVE)-b-PVAc}

Poly(CTFE-alt-BVE) (0.783 g) bearing a xanthate end-group as a macro chain transfer agent (macro-CTA) was dissolved in $5 \mathrm{~mL}$ ethyl acetate and charged in a $10 \mathrm{~mL}$ glass tube with $3.0 \mathrm{mg}$ AIBN $(0.018 \mathrm{mmol})$ as well as $1.5 \mathrm{~mL}$ VAc $(16.2 \mathrm{mmol})$. Three cycles of freeze-vacuum-thaw were conducted to remove any traces of oxygen. After sealing under vacuum, the tube was immersed in a thermostatic oil bath at $70^{\circ} \mathrm{C}$ for $6 \mathrm{~h}$. Then the tube was cooled down by ice water to stop the polymerization, and the solution was precipitated into methanol. Purification was carried out by repeating dissolution in ethyl acetate and precipitation from methanol. The resultant polymer was collected and dried under vacuum at $50{ }^{\circ} \mathrm{C}$ until a constant weight. The conversion of VAc was determined by gravimetry.

\subsubsection{Synthesis of Poly(CTFE-alt-BVE)-b-PVA}

A mixture of $0.806 \mathrm{~g}$ poly(CTFE-alt-BVE)- $b$-PVAc in $20 \mathrm{~mL}$ THF and $0.200 \mathrm{~g} \mathrm{NaOH}(5.00 \mathrm{mmol}$ ) in $20 \mathrm{~mL}$ methanol was introduced into a $100 \mathrm{~mL}$ round-bottom flask equipped with a condenser and a magnetic stirrer. Then it was immersed in an oil bath at $40^{\circ} \mathrm{C}$ and stirred for $6 \mathrm{~h}$. After cooling to room temperature, the solution was concentrated and precipitated in methanol. A similar purification process as the one descripted above was conducted by repeating dissolution in THF and precipitation from methanol in order to remove the residual base and the salt produced during the reaction. The resultant block polymer was dried under vacuum at $50{ }^{\circ} \mathrm{C}$ until a constant weight.

\subsubsection{Preparation of the Fluorinated Polyurethane Coating}

A mixture of poly(CTFE-alt-BVE)- $b$-PVA ( $0.56 \mathrm{~g})$, IPDI ( $0.10 \mathrm{~g}, 0.45 \mathrm{mmol})$, and DBTDL (0.56 mg, $8.9 \times 10^{-4} \mathrm{mmol}$, added by taking $100 \mu \mathrm{L}$ dilute solution of DBTDL in THF with a concentration of $5.6 \mathrm{mg} \cdot \mathrm{cm}^{-3}$ ) in $10 \mathrm{~mL}$ THF was charged in a $25 \mathrm{~mL}$ round-bottom flask equipped with a condenser and a magnetic stirrer. The solution was stirred at $65^{\circ} \mathrm{C}$ for $10 \mathrm{~h}$. The fluorinated polyurethane coating was prepared by casting the viscous solution onto glass plates, drying at $70^{\circ} \mathrm{C}$ for $12 \mathrm{~h}$, and further drying at $80^{\circ} \mathrm{C}$ for $12 \mathrm{~h}$ in a vacuum oven to remove any residual solvent and enhance the crosslinking reaction.

\section{Results and Discussion}

Table 1 shows the results of RAFT/MADIX copolymerization of CTFE and BVE. The theoretical molar masses $\left(M_{n, t h}\right)$ and the molar masses determined by ${ }^{1} \mathrm{H}$ NMR spectra $\left(M_{n, N M R}\right)$ of poly(CTFE-alt-BVE) were respectively calculated according to Equation (1) and (2):

$$
\begin{gathered}
M_{n, t h}=\left([\mathrm{BVE}]_{0} /[\mathrm{BEDTC}]_{0}\right) \times \text { Conv. } \times\left(M_{\mathrm{CTFE}}+M_{B V E}\right)+M_{B E D T C} \\
M_{n, N M R}=\left(I_{3.76} / I_{7.35}\right) \times 2.5 \times\left(M_{C T F E}+M_{B V E}\right)+M_{B E D T C}
\end{gathered}
$$

where $[\mathrm{BVE}]_{0} /[\mathrm{BEDTC}]_{0}$ is the initial molar ratio of BVE to BEDTC, Conv. is the conversion of be, $M_{C T F E}, M_{B V E}$, and $M_{B E D T C}$ stand for the molar mass of CTFE, be, and BEDTC, respectively, $I_{3.76}$ and $I_{7.35}$ are the integral values of ${ }^{1} \mathrm{H}$ NMR signal peaks of poly(CTFE-alt-BVE) centered at 3.76 and $7.35 \mathrm{ppm}$, which belong to the side butoxyl groups $\left(-\mathrm{OCH}_{2} \mathrm{CH}_{2} \mathrm{CH}_{2} \mathrm{CH}_{3}\right)$ and the phenyl end groups of BEDTC, respectively. 
Table 1. Results of RAFT/MADIX copolymerization of CTFE and BVE.

\begin{tabular}{ccccccc}
\hline Sample & Time/h & Conv. ${ }^{\mathbf{1}}$ & $\boldsymbol{M}_{\boldsymbol{n}, \boldsymbol{t h}}$ & $\boldsymbol{M}_{\boldsymbol{n}, \boldsymbol{N M R}}$ & $\boldsymbol{M}_{\boldsymbol{n}, \mathbf{G P C}}$ & $\boldsymbol{M}_{\boldsymbol{w}} / \boldsymbol{M}_{\boldsymbol{n}}$ \\
\hline P1 & 1 & 0.11 & 2500 & 2400 & 4600 & 1.41 \\
P2 & 2 & 0.22 & 5000 & 5200 & 6900 & 1.38 \\
P3 & 3 & 0.31 & 6900 & 7300 & 8900 & 1.43 \\
P4 & 4 & 0.40 & 8900 & 8500 & 10,900 & 1.37 \\
P5 & 5 & 0.50 & 11,000 & 11,000 & 13,000 & 1.37 \\
P6 & 6 & 0.56 & 12,300 & 12,200 & 14,500 & 1.35 \\
P7 & 9 & 0.66 & 14,500 & 14,800 & 16,800 & 1.39 \\
\hline \multicolumn{7}{c}{ 1 Conversion of BVE measured by gravimetry. }
\end{tabular}

As shown in Table 1, the molar masses of poly(CTFE-alt-BVE) calculated from the ${ }^{1} \mathrm{H}$ NMR spectra are close to the theoretical values. Although the molar masses determined by GPC $\left(M_{n, G P C}\right)$ were systematically higher than the theoretical values because of the polystyrene standards used in the calibration, the dispersities were narrow.

Figure 1a reveals the evolution of the molar mass and dispersity as functions of monomer conversion during copolymerization of CTFE and BVE. It can be observed that the molar mass of poly(CTFE-alt-BVE) increased linearly with the monomer conversion, and the dispersity values remained small. Moreover, a linear relationship between $\ln \left([\mathrm{M}]_{0} /[\mathrm{M}]\right)$ and the polymerization time is shown in Figure 1b, which indicates that the polymerization was a first-order reaction with respect to BVE concentration, and the number of active radicals remained constant during the polymerization [70]. All these results demonstrate that a living/controlled copolymerization of CTFE and BVE took place under the chosen reaction condition.


Figure 1. Kinetics of the copolymerization of CTFE and BVE: (a) molar mass and dispersity as functions of monomer conversion; (b) monomer conversion and $\ln \left([\mathrm{M}]_{0} /[\mathrm{M}]\right)$ as a function of polymerization time.

The chemical structure of the obtained copolymer was characterized by ${ }^{19} \mathrm{~F},{ }^{13} \mathrm{C}$, and ${ }^{1} \mathrm{H} N M R$ spectroscopy, and the sample $\mathrm{P} 4$ was chosen as a representative sample. It showsed a series of multiplets centered at $-109.4,-116.8,-119.6$, and $-121.6 \mathrm{ppm}$ in the ${ }^{19} \mathrm{~F}$ NMR spectrum (Figure 2a), which can be related to the constitutive $\mathrm{CF}_{2}$ and $\mathrm{CFCl}$ groups of the chain backbone [83]. Furthermore, the absence of peaks at $-100 \mathrm{ppm}$ [84] and $-127 \mathrm{ppm}$ [85] in ${ }^{19} \mathrm{~F}$ NMR spectrum indicates that there were no CTFE-CTFE diads in the polymer chains, whi ch is a remarkable evidence of the alternating structure of poly(CTFE-alt-BVE), given that BVE cannot homopolymerize at those radical polymerization conditions. Figure $2 \mathrm{~b}$ shows the ${ }^{13} \mathrm{C}$ NMR spectrum of poly(CTFE-alt-BVE). The signal around $70.0 \mathrm{ppm}$ and the weak signal around $212.3 \mathrm{ppm}$ were ascribed to the methylene linked to the oxygen atom and the quaternary carbon in the structure of $-\mathrm{S}-\mathrm{C}(=\mathrm{S})-\mathrm{O}-\mathrm{H}_{2}-\mathrm{CH}_{3}$ at the chain end of the polymer, respectively. The signals located between 127 and $131 \mathrm{ppm}$ were assigned to the carbon atoms of phenyl groups. 
(a)

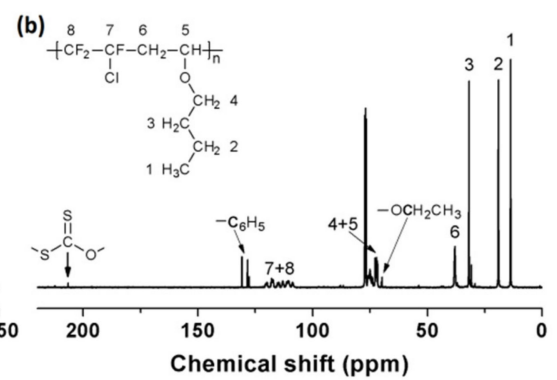

Figure 2. (a) ${ }^{19} \mathrm{~F}$ and (b) ${ }^{13} \mathrm{C}$ NMR spectra of poly(CTFE-alt-BVE) (Sample P4).

Figure 3a shows the ${ }^{1} \mathrm{H}$ NMR spectrum of poly(CTFE-alt-BVE). The resonances centered at 4.60 and $4.41 \mathrm{ppm}$ were attributed to the protons of methine in the structure of - $\mathrm{CTFE}-\mathrm{CH}_{2}-\mathrm{CH}(\mathrm{OBu})-\mathrm{CTFE}-$, and the split arose from the chiral carbons in the polymer chain. The broad peaks located at $2.40-3.30 \mathrm{ppm}$ were ascribed to the methylene of the BVE units in the polymer backbone (Supplementary Section 2), and the resonances at $3.76,1.58,1.38$, and $0.93 \mathrm{ppm}$ to the side butoxyl groups. In addition, the peaks at $7.35 \mathrm{ppm}$ belonged to the phenyl end groups of BEDTC (As shown in Figures S1 and S2), indicating that a chain transfer reaction occurred. The signals of the ethoxyl groups overlapped with those of the polymer backbone.

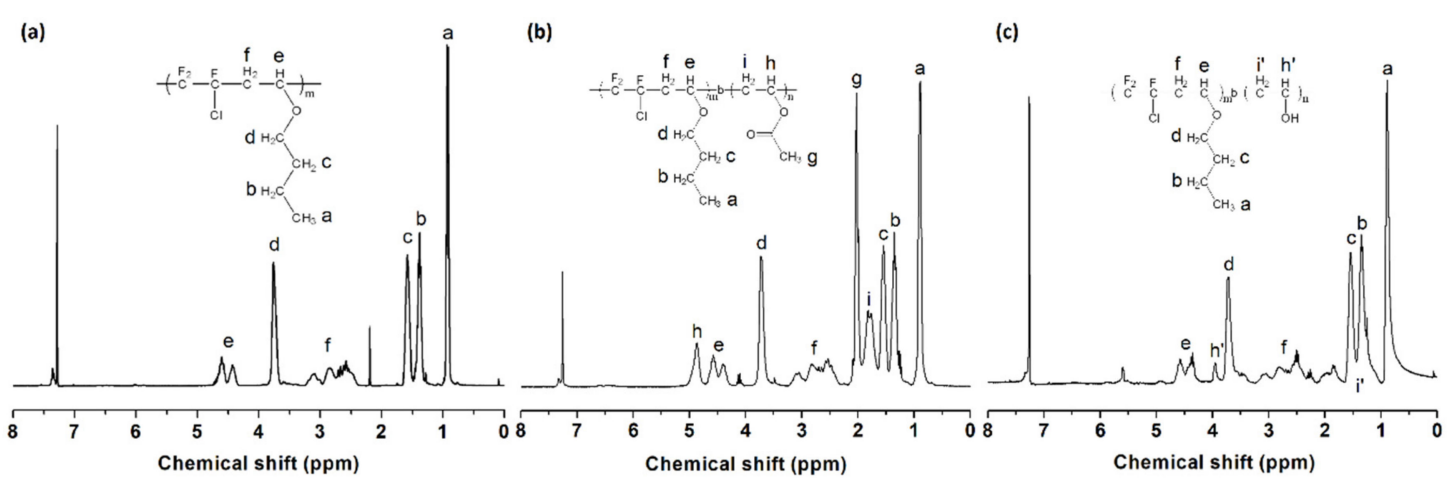

Figure 3. ${ }^{1} \mathrm{H}$ NMR spectra of (a) poly(CTFE-alt-BVE) (Sample P4), (b) poly(CTFE-alt-BVE)-b-PVAc, and (c) poly(CTFE-alt-BVE)-b-PVA.

Chain extension polymerization was performed using Sample P4 as a macro-CTA and VAc as the monomer. Figure 4 shows the GPC traces of the obtained block copolymer (poly(CTFE-alt-BVE)- $b$-PVAc) and the macro-CTA. A symmetrical and monomodal curve for the block copolymer with a shift toward a higher molecular weight related to the curve of the macro-CTA in the GPC traces indicates that the chain extension polymerization was successfully achieved and the dispersity of the block copolymer was still low.

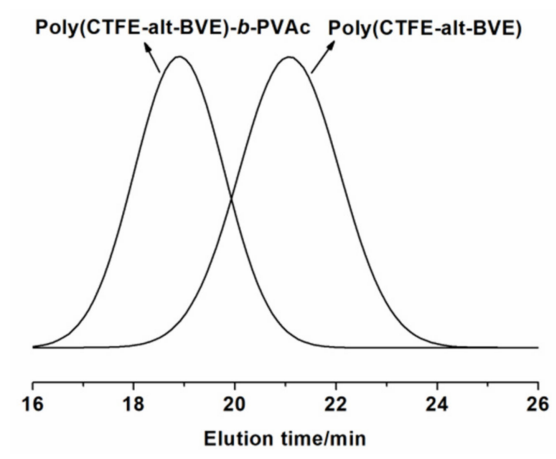

Figure 4. GPC traces of poly(CTFE-alt-BVE) (Sample P4, $M_{n, G P C}=10900, M_{w} / M_{n}=1.37$ ) and poly(CTFE-alt-BVE)- $b$-PVAc $\left(M_{n, G P C}=17200, M_{w} / M_{n}=1.32\right)$.e. 
The obtained poly(CTFE-alt-BVE)-b-PVAc was characterized by ${ }^{1} \mathrm{H}$ NMR spectroscopy (Figure $3 b$ ). Some new signal peaks appeared compared to the spectrum of poly(CTFE-alt-BVE). The resonance signals centered at 1.79 and $4.87 \mathrm{ppm}$ can be attributed to the protons of the methene and methine groups in the VAc unit, respectively. A single peak signal appeared at $2.02 \mathrm{ppm}$, which belongs to the methyl groups of the VAc units. The block copolymer, poly(CTFE-alt-BVE)-b-PVAc, was then hydrolyzed in basic methanol, and the resulting amphiphilic block copolymer, poly(CTFE-alt-BVE)-b-PVA, was confirmed by ${ }^{1} \mathrm{H}$ NMR and FT-IR spectroscopy. Figure $3 \mathrm{c}$ shows the ${ }^{1} \mathrm{H}$ NMR spectrum of poly(CTFE-alt-BVE)-b-PVA. As can be seen, the signal peaks attributed to the VAc unit almost disappeared, and new resonance signals belonging to the vinyl alcohol (VA) unit were recorded. The resonance signal centered at $3.95 \mathrm{ppm}$ belongs to the methine groups in the VA unit, while the resonance signal of the methene group in the VA unit overlaps with that of the butoxyl group in the BVE unit. Figure 5a shows the FT-IR spectra of poly(CTFE-alt-BVE)- $b$-PVAc and poly(CTFE-alt-BVE)-b-PVA. The strong absorption band of the $\mathrm{C}=\mathrm{O}$ bond at $1740 \mathrm{~cm}^{-1}$ in the VAc unit almost completely disappeared after hydrolysis, and a new band at $3378 \mathrm{~cm}^{-1}$ appeared, which could be attributed to stretching vibration of the $\mathrm{O}-\mathrm{H}$ bond in the VA unit.
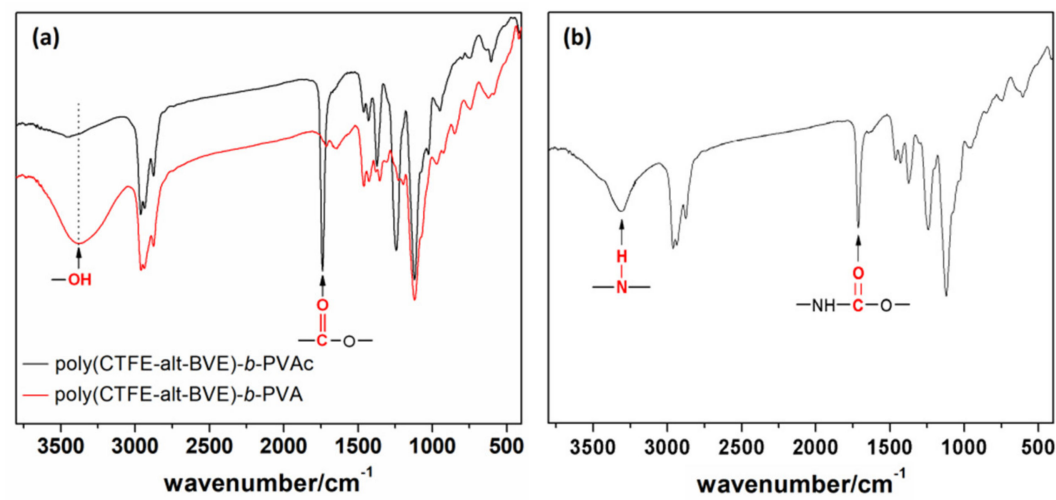

Figure 5. FT-IR spectra of (a) poly(CTFE-alt-BVE)-b-PVAc, poly(CTFE-alt-BVE)- $b$-PVA, and (b) the fluorinated polyurethane.

Figure $5 \mathrm{~b}$ shows the FT-IR spectrum of the fluorinated polyurethane. As can be seen, characteristic peaks of the $\mathrm{N}-\mathrm{H}$ bond at $3305 \mathrm{~cm}^{-1}$ and of the $\mathrm{C}=\mathrm{O}$ bond at $1715 \mathrm{~cm}^{-1}$ clearly appeared in the spectrum, which demonstrates the successful preparation of the fluorinated polyurethane [38,39].

The surface composition of the fluorinated polyurethane coating was studied by XPS analysis (Figure 6a). The XPS measurement showed the photoionization peaks of chlorine, carbon, oxygen, and fluorine in the survey spectrum, but no peak attributed to nitrogen was detected. In fact, the XPS spectrum of the fluorinated polyurethane was very similar to that of poly(CTFE-alt-BVE) (Figure 6b). This was probably due to the low free energy of fluorine and the mobility of the flexible fluorinated polymer chains linked to the coating network, which led the poly(CTFE-alt-BVE) blocks to the outermost surface of the coating [54]. 

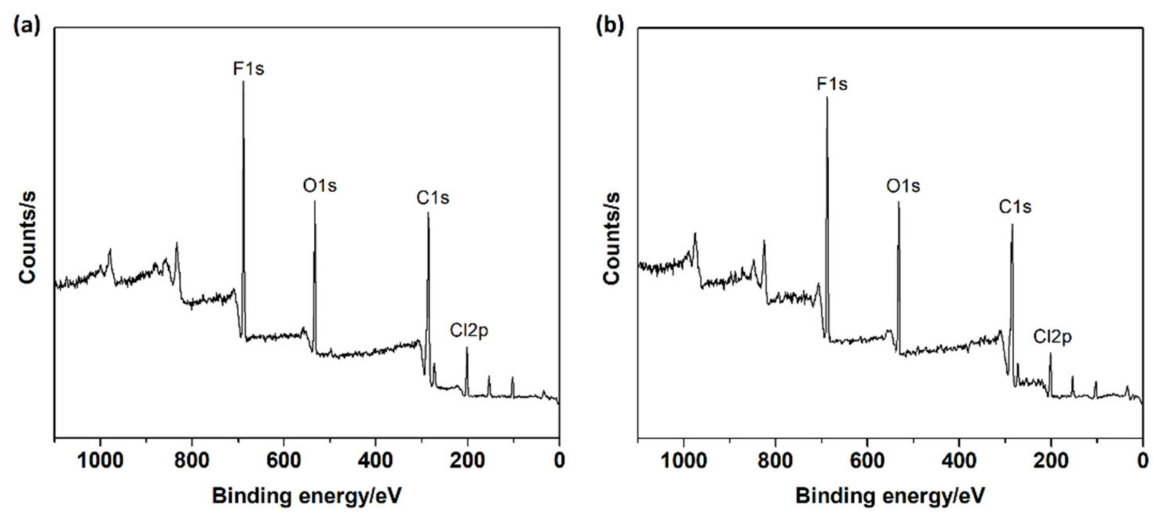

Figure 6. X-ray photoelectron spectroscopy (XPS) survey spectra of (a) the fluorinated polyurethane coating and (b) poly(CTFE-alt-BVE) coating (Sample P4).

The surface properties of the fluorinated polyurethane coating were evaluated by static contact angle measurements (Figure 7). The water contact angle of the fluorinated polyurethane coating was $108^{\circ}$, which is equal to the value of the viscous coating made of poly(CTFE-alt-BVE). This results was consistent with the above-mentioned XPS analysis result.

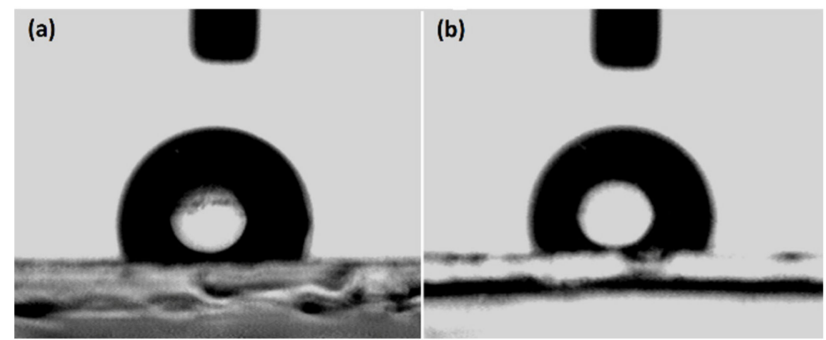

Figure 7. Photographs taken during static water contact angle measurements: (a) fluorinated polyurethane coating, (b) poly(CTFE-alt-BVE) coating (Sample P4).

The thermostability of the fluorinated polyurethane was characterized by TGA (Figure 8). According to the TGA thermogram, the decomposition temperature of the fluorinated polyurethane at $5 \%$ weight loss was about $277^{\circ} \mathrm{C}$, which demonstrates that the fluorinated polyurethane prepared in this work had good thermal stability, although it was a bit lower than that of poly(CTFE-alt-BVE).

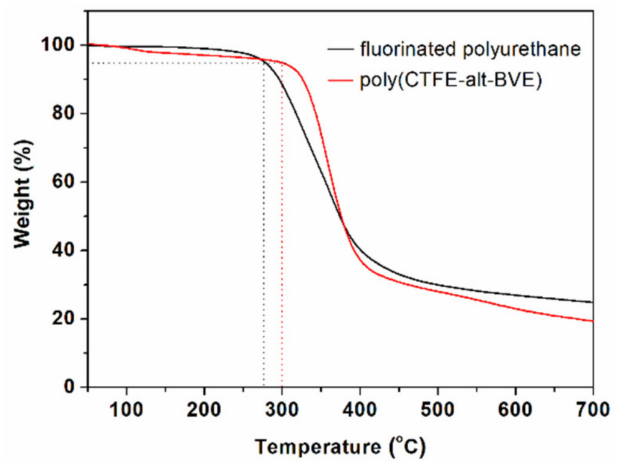

Figure 8. TGA thermograms of the fluorinated polyurethane (black) and of poly(CTFE-alt-BVE) (red, Sample P4).

The prepared fluorinated polyurethane coating is not any more viscous than the initial poly(CTFE-alt-BVE) and is insoluble in common organic solvents, such as ethyl acetate, acetone, $\mathrm{CHCl}_{3}$, and $\mathrm{THF}$, which improves the applicability of this material. Table 2 shows the chemical 
resistance of the fluorinated polyurethane and of poly(CTFE-alt-BVE). As can be seen, the fluorinated polyurethane has an excellent chemical resistance due to the presence of fluorinated chains and a crosslinking structure.

Table 2. Chemical resistance of the fluorinated polyurethane and of poly(CTFE-alt-BVE).

\begin{tabular}{ccccccccc}
\hline & \multicolumn{7}{c}{ Solvent } \\
\cline { 2 - 9 } Sample $^{\mathbf{1}}$ & Water & $\begin{array}{c}\mathbf{H}_{\mathbf{2}} \mathbf{S O}_{\mathbf{4}} \\
\mathbf{( 1 0} \mathbf{~ w t} \mathbf{0})\end{array}$ & $\begin{array}{c}\mathbf{N a O H} \\
\mathbf{( 1 0} \mathbf{~ w t} \%)\end{array}$ & Ethyl Acetate & Acetone & Ethanol & $\mathbf{C H C l}_{\mathbf{3}}$ & $\mathbf{T H F}$ \\
\hline FPU & 10 & 10 & 10 & 8 & 8 & 10 & 8 & 8 \\
PCB & 10 & 10 & 10 & 0 & 0 & 10 & 2 & 0 \\
\hline \multicolumn{7}{c}{${ }^{1}$ FPU: fluorinated polyurethane, PCB: poly(CTFE-alt-BVE). }
\end{tabular}

\section{Conclusions}

Living/controlled radical copolymerization of CTFE and BVE has been successfully achieved using BEDTC as a chain transfer agent and AIBN as an initiator at $70^{\circ} \mathrm{C}$. After a chain extension reaction with VAc and a basic methanolysis process, a fluorinated amphiphilic polymer was prepared. Based on this, a novel fluorinated polyurethane with flexible fluorinated polymer chains linked to the network was successfully synthesized, which could be used for coating or in some other applications.

Supplementary Materials: The following are available online at http://www.mdpi.com/2073-4360/11/9/1440/s1, Figure S1. 1H NMR spectrum of BEDTC recorded in CDCl3 at room temperature; Figure S2. 13C NMR spectrum of BEDTC recorded in $\mathrm{CDCl} 3$ at room temperature.

Author Contributions: Investigation, P.-C.W., D.L., and H.W.; data curation, P.-C.W.; writing-original draft preparation, P.-C.W.; writing-review and editing, R.-K.B.

Funding: This research was funded by Science Challenge Project (TZ2018004) and National Natural Science Foundation (NNSF) of China (NO. 21504086 and U1530259).

Conflicts of Interest: The authors declare no conflict of interest.

\section{References}

1. Wehbi, M.; Banerjee, S.; Mehdi, A.; Alaaeddine, A.; Hachem, A.; Ameduri, B. Vinylidene Fluoride-Based Polymer Network via Cross-Linking of Pendant Triethoxysilane Functionality for Potential Applications in Coatings. Macromolecules 2017, 50, 9329-9339. [CrossRef]

2. Game, P.; Sage, D.; Chapel, J.P. Surface Mobility of Polyurethane Networks Containing Fluorinated Amphiphilic Reactive Additives. Macromolecules 2002, 35, 917-923. [CrossRef]

3. McCloskey, C.B.; Yip, C.M.; Santerre, J.P. Effect of Fluorinated Surface-Modifying Macromolecules on the Molecular Surface Structure of a Polyether Poly(urethane urea). Macromolecules 2002, 35, 924-933. [CrossRef]

4. Wang, L.F. Effect of soft segment length on the thermal behaviors of fluorinated polyurethanes. Eur. Polym. J. 2005, 41, 293-301. [CrossRef]

5. Chattopadhyay, D.K.; Raju, K.V.S.N. Structural engineering of polyurethane coatings for high performance applications. Prog. Polym. Sci. 2007, 32, 352-418. [CrossRef]

6. Turri, S.; Valsecchi, R.; Levi, M.; Cristini, M.; Sanguineti, A. Microstructure to property relations in a family of millable polyurethane fluoroelastomers. Eur. Polym. J. 2008, 44, 2951-2961. [CrossRef]

7. Xu, W.; Lu, B.; Hu, Y.; Song, L.; Nie, S. Synthesis and characterization of novel fluorinated polyurethane elastomers based on 2,2-bis[4-(4-amino-2-trifluoromehyloxyphenyl) phenyl]propane. Polym. Adv. Technol. 2012, 23, 877-883. [CrossRef]

8. Ge, J.; Si, Y.; Fu, F.; Wang, J.; Yang, J.; Cui, L.; Sun, G. Amphiphobic fluorinated polyurethane composite microfibrous membranes with robust waterproof and breathable performances. RSC Adv. 2013, 3, 2248-2255. [CrossRef]

9. Wang, C.; Li, X.; Du, B.; Li, P.; Lai, X.; Niu, Y. Preparation and properties of a novel waterborne fluorinated polyurethane-acrylate hybrid emulsion. Colloid. Polym. Sci. 2014, 292, 579-587. [CrossRef] 
10. Lin, J.; Jiang, F.; Wen, J.; Lv, W.; Porteous, N.; Deng, Y.; Sun, Y. Fluorinated and Un-fluorinated N-halamines as Antimicrobial and Biofilm-controlling Additives for Polymers. Polymer 2015, 68, 92-100. [CrossRef]

11. Zhang, L.; Li, Y.; Yu, J.; Ding, B. Fluorinated polyurethane macroporous membranes with waterproof, breathable and mechanical performance improved by lithium chloride. RSC Adv. 2015, 5, 79807-79814. [CrossRef]

12. Sheng, J.; Zhang, M.; Luo, W.; Yu, J.; Ding, B. Thermally induced chemical cross-linking reinforced fluorinated polyurethane/polyacrylonitrile/polyvinyl butyral nanofibers for waterproof-breathable application. RSC Adv. 2016, 6, 29629-29637. [CrossRef]

13. Li, N.; Zeng, F.L.; Wang, Y.; Qu, D.Z.; Zhang, C.; Li, J.; Bai, Y.P. Synthesis and characterization of fluorinated polyurethane containing carborane in the main chain: thermal, mechanical and chemical resistance properties. Chin. J. Polym. Sci. 2018, 36, 85-97. [CrossRef]

14. Pali-Casanova, R.; Yam-Cervantes, M.; Zavala-Loría, J.; Loría-Bastarrachea, M.; Aguilar-Vega, M.; Dzul-López, L.; Sámano-Celorio, M.; Crespo-Álvarez, J.; García-Villena, E.; Agudo-Toyos, P.; et al. Effect of Sulfonic Groups Concentration on IEC Properties in New Fluorinated Copolyamides. Polymers 2019, 11, 1169. [CrossRef]

15. Rodríguez-Alabanda, Ó.; Romero, P.; Soriano, C.; Sevilla, L.; Guerrero-Vaca, G. Study on the Main Influencing Factors in the Removal Process of Non-Stick Fluoropolymer Coatings Using Nd:YAG Laser. Polymers 2019, 11, 123. [CrossRef] [PubMed]

16. Wang, P.; Wang, H.; Dong, Q.; Bai, R. Cobalt-Mediated Radical Copolymerization of Chlorotrifluoroethylene and Vinyl Acetate. Polymers 2019, 11, 101. [CrossRef] [PubMed]

17. Jiang, M.; Zhao, X.; Ding, X.; Zheng, Z.; Peng, Y. A novel approach to fluorinated polyurethane by macromonomer copolymerization. Eur. Polym. J. 2005, 41, 1798-1803. [CrossRef]

18. Chapman, T.M.; Marra, K.G. Determination of Low Critical Surface Tensions of Novel Fluorinated Poly(amide urethane) Block Copolymers. 2. Fluorinated Soft-Block Backbone and Side Chains. Macromolecules 1995, 28, 2081-2085. [CrossRef]

19. Rahman, M.M.; Lee, I.; Chun, H.H.; Kim, H.D.; Park, H. Properties of waterborne polyurethane-fluorinated marine coatings: The effect of different types of diisocyanates and tetrafluorobutanediol chain extender content. J. Appl. Polym. Sci. 2014, 131, 39905. [CrossRef]

20. Wang, S.; Liu, W.; Tan, J. Synthesis and properties of fluorine containing polyurethane based on long chain fluorinated polyacrylate. J. Macromol. Sci. Part. A 2016, 53, 41-48. [CrossRef]

21. Su, S.-K.; Gu, J.-H.; Lee, H.-T.; Yu, S.-H.; Wu, C.-L.; Suen, M.-C. Effects of an Aromatic Fluoro-Diol and Polycaprolactone on the Properties of the Resultant Polyurethanes. Adv. Polym. Tech. 2018, 37, 1142-1152. [CrossRef]

22. Takakura, T.; Kato, M.; Yamabe, M. Fluorinated polyurethanes, 1. Synthesis and characterization of fluorine-containing segmented poly(urethane-urea)s. Macromol. Chem. Phys. 1990, 191, 625-632. [CrossRef]

23. Posada, F.; Gardette, J.L. Photo-oxidation of cured fluorinated polymers IV. Photo-oxidation of the fluorinated copolymer network with urethane linkage. Polym. Degrad. Stab. 2000, 70, 17-29. [CrossRef]

24. Luda, M.P.; Camino, G.; Laurenti, E.; Novelli, S.; Temtchenko, T.; Turri, S. Mechanism of photostabilization of perfluoropolyether coatings by hindered amine stabilisers. Polym. Degrad. Stab. 2001, 73, 387-392. [CrossRef]

25. Bassi, M.; Tonelli, C.; Di Meo, A. Glass Transition Behavior of a Microphase Segregated Polyurethane Based on PFPE and IPDI. A Calorimetric Study. Macromolecules 2003, 36, 8015-8023. [CrossRef]

26. Chen, K.Y.; Kuo, J.F. Influence of fluorocarbon chains on the crystallization behaviors of aliphatic polyurethanes. J. Appl. Polym. Sci. 2009, 111, 371-379. [CrossRef]

27. Wang, Z.; Hou, Z.; Wang, Y. Fluorinated waterborne shape memory polyurethane urea for potential medical implant application. J. Appl. Polym. Sci. 2013, 127, 710-716. [CrossRef]

28. Du, Y.; Yang, Z.; Zhou, C. Study on waterborne polyurethanes based on poly(dimethyl siloxane) and perfluorinated polyether. Macromol. Res. 2015, 23, 867-875. [CrossRef]

29. Wang, X.; Xu, J.; Li, L.; Liu, Y.; Li, Y.; Dong, Q. Influences of fluorine on microphase separation in fluorinated polyurethanes. Polymer 2016, 98, 311-319. [CrossRef]

30. Boutevin, B.; Hugon, I.P.; Pietrasanta, Y. Synthese et caracterisation de polyurethanes fluores-II: Étude des polyuréthanes. Eur. Polym. J. 1981, 17, 729-734. [CrossRef]

31. Boutevin, B.; Hugon, I.P.; Pietrasanta, Y. Synthese et caracterisation de polyurethanes flugres-I: Etude de molecules modeles. Eur. Polym. J. 1981, 17, 723-727. [CrossRef] 
32. Tan, H.; Liu, J.; Li, J.; Jiang, X.; Xie, X.; Zhong, Y.; Fu, Q. Synthesis and Hemocompatibility of Biomembrane Mimicing Poly(carbonate urethane)s Containing Fluorinated Alkyl Phosphatidylcholine Side Groups. Biomacromolecules 2006, 7, 2591-2599. [CrossRef] [PubMed]

33. Lin, Y.H.; Liao, K.H.; Chou, N.K.; Wang, S.S.; Chu, S.H.; Hsieh, K.H. UV-curable low-surface-energy fluorinated poly(urethane-acrylate)s for biomedical applications. Eur. Polym. J. 2008, 44, 2937. [CrossRef]

34. Shevchenko, V.V.; Sidorenko, A.V.; Bliznyuk, V.N.; Tkachenko, I.M.; Shekera, O.V.; Smirnov, N.N.; Tsukruk, V.V. Synthesis and properties of hydroxylated core-fluorinated diamines and polyurethanes based on them with azobenzene nonlinear optical chromophores in the backbone. Polymer 2013, 54, 6516-6525. [CrossRef]

35. Wu, C.L.; Chiu, S.H.; Lee, H.T.; Suen, M.C. Synthesis and properties of biodegradable polycaprolactone/polyurethanes using fluoro chain extenders. Polym. Adv. Technol. 2016, 27, 665-676. [CrossRef]

36. Yang, L.; Wang, Y.; Peng, X. Synthesis and characterization of novel fluorinated thermoplastic polyurethane with high transmittance and superior physical properties. J. Macromol. Sci. Part. A 2017, 54, 516-523. [CrossRef]

37. Li, N.; Zeng, F.; Wang, Y.; Qu, D.; Hu, W.; Luan, Y.; Dong, S.; Zhang, J.; Bai, Y. Fluorinated polyurethane based on liquid fluorine elastomer (LFH) synthesis via two-step method: the critical value of thermal resistance and mechanical properties. RSC Adv. 2017, 7, 30970-30978. [CrossRef]

38. Ge, Z.; Zhang, X.; Dai, J.; Li, W.; Luo, Y. Study of Surface Properties of Novel Fluorinated Polyurethanes with Fluorine-Containing Pendent Groups. J. Macromol. Sci. Part. A 2009, 46, 215-221. [CrossRef]

39. Ge, Z.; Zhang, X.; Dai, J.; Li, W.; Luo, Y. Synthesis, characterization and properties of a novel fluorinated polyurethane. Eur. Polym. J. 2009, 45, 530-536. [CrossRef]

40. Ho, T.; Wynne, K.J. A new fluorinated polyurethane polymerization, characterization, and mechanical properties. Macromolecules 1992, 25, 3521-3527. [CrossRef]

41. Liu, P.; Ye, L.; Liu, Y.; Nie, F. Preparation and properties of the main-chain-fluorinated thermoplastic polyurethane elastomer. Polym. Bull. 2010, 66, 503-515. [CrossRef]

42. Fournier, D.; Du Prez, F. "Click" Chemistry as a Promising Tool for Side-Chain Functionalization of Polyurethanes. Macromolecules 2008, 41, 4622-4630. [CrossRef]

43. Zhu, M.J.; Qing, F.L.; Meng, W.D. Novel waterborne polyurethanes containing short fluoroalkyl chains: Synthesis and applications on cotton fabrics. J. Appl. Polym. Sci. 2008, 109, 1911-1915. [CrossRef]

44. Pilch-Pitera, B. Blocked polyisocyanates containing fluorine atoms as crosslinking agents for polyurethane powder coatings. J. Appl. Polym. Sci. 2012, 124, 3302-3311. [CrossRef]

45. Zhang, Y.; Wang, L.; Zhang, Z.; Zhang, Y.; Tuo, X. Synthesis and simultaneous self-assembly of multiblock fluorinated polyurethane in iniferter polymerization. J. Polym. Sci. Part. A Polym. Chem. 2013, 51, 2161-2170. [CrossRef]

46. Yang, W.; Pan, P.; Wang, H.; Cheng, X.; Du, Z. Effect of hydroxyl-terminated poly(fluoroalkyl methacrylate) main-chain length on the microphase separation of waterborne fluorinated polyurethane. Polym. Int. 2018, 67, 1054-1061. [CrossRef]

47. Zhang, X.; Jiang, X.; Li, J.; Tan, H.; Zhong, Y.; Fu, Q. Surface and bulk properties of poly(ether urethane)s/fluorinated phosphatidylcholine polyurethanes blends. J. Appl. Polym. Sci. 2008, 108, 548-553. [CrossRef]

48. Jiang, G.; Tuo, X.; Wang, D.; Li, Q. Preparation, characterization, and properties of fluorinated polyurethanes. J. Polym. Sci., Part. A Polym. Chem. 2009, 47, 3248-3256. [CrossRef]

49. Park, J.M.; Lee, Y.H.; Park, H.; Kim, H.D. Preparation and properties of UV-curable fluorinated polyurethane acrylates. J. Appl. Polym. Sci. 2014, 131, 40603. [CrossRef]

50. Jeon, J.H.; Park, Y.G.; Lee, Y.H.; Lee, D.J.; Kim, H.D. Preparation and properties of UV-curable fluorinated polyurethane acrylates containing crosslinkable vinyl methacrylate for antifouling coatings. J. Appl. Polym. Sci. 2015, 132, 42168. [CrossRef]

51. Jia, R.P.; Zong, A.X.; He, X.Y.; Xu, J.Y.; Huang, M.S. Synthesis of newly fluorinated thermoplastic polyurethane elastomers and their blood compatibility. Fibers Polym. 2015, 16, 231-238. [CrossRef]

52. Park, J.M.; Jeon, J.H.; Lee, Y.H.; Lee, D.J.; Park, H.; Chun, H.H.; Do Kim, H. Synthesis and properties of UV-curable polyurethane acrylates containing fluorinated acrylic monomer/vinyltrimethoxysilane. Polym. Bull. 2015, 72, 1921-1936. [CrossRef] 
53. Su, S.K.; Gu, J.H.; Lee, H.T.; Wu, C.L.; Hwang, J.J.; Suen, M.C. Synthesis and properties of novel biodegradable polyurethanes containing fluorinated aliphatic side chains. J. Polym. Res. 2017, 24, 142. [CrossRef]

54. Shi, X.; Shi, H.; Wu, H.; Shen, H.; Cao, P. Synthesis and properties of novel fluorinated polyurethane based on fluorinated gemini diol. Polym. Adv. Technol. 2018, 29, 1939-1952. [CrossRef]

55. Tan, J.; Liu, W.; Wang, Z. Preparation and performance of waterborne UV-curable polyurethane containing long fluorinated side chains. J. Appl. Polym. Sci. 2017, 134, 44506. [CrossRef]

56. Chen, M.; Ou, B.; Guo, Y.; Guo, Y.; Kang, Y.; Liu, H.; Yan, J.; Tian, L. Preparation of an environmentally friendly antifouling degradable polyurethane coating material based on medium-length fluorinated diols. J. Macromol. Sci. Part. A 2018, 55, 483-488. [CrossRef]

57. Yu, Y.; Wang, J.; Zong, J.; Zhang, S.; Deng, Q.; Liu, S. Synthesis of a fluoro-diol and preparation of fluorinated waterborne polyurethanes with high elongation at break. J. Macromol. Sci. Part. A 2017, 55, 183-191. [CrossRef]

58. Chapman, T.M.; Benrashid, R.; Gribbin, K.L.; Keener, J.P. Determination of Low Critical Surface Energies of Novel Fluorinated Poly(amide urethane) Block Copolymers. 1. Fluorinated Side Chains. Macromolecules 1995, 28, 331-335. [CrossRef]

59. Tan, D.S.; Zhang, X.Q.; Wang, J.C.; Li, J.H.; Tan, H.; Fu, Q. Synthesis and phase behavior of polyurethanes end-capped with fluorinated phosphatidylcholine head groups. Chin. J. Polym. Sci. 2011, 29, 615-626. [CrossRef]

60. Zhu, Q.; Han, C.C. Study of telechelic polyurethane with perfluoropolyether tails. Polymer 2010, 51, 877-882. [CrossRef]

61. Penoff, M.; Schreiner, W.; Oyanguren, P.; Montemartini, P. Fluorinated Polyurethanes: XPS and AFM Characterization. Macromol. Symp. 2012, 321, 186-190. [CrossRef]

62. Mao, X.; Chen, Y.; Si, Y.; Li, Y.; Wan, H.; Yu, J.; Ding, B. Novel fluorinated polyurethane decorated electrospun silica nanofibrous membranes exhibiting robust waterproof and breathable performances. RSC Adv. 2013, 3, 7562-7569. [CrossRef]

63. Gennen, S.; Grignard, B.; Thomassin, J.M.; Gilbert, B.; Vertruyen, B.; Jerome, C.; Detrembleur, C. Polyhydroxyurethane hydrogels: Synthesis and characterizations. Eur. Polym. J. 2016, 84, 849-862. [CrossRef]

64. Li, P.; Shen, Y.; Yang, X.; Li, G. Preparation and properties of waterborne cationic fluorinated polyurethane. J. Polym. Res. 2012, 19, 9786. [CrossRef]

65. Esteves, A.C.C.; Lyakhova, K.; van der Ven, L.G.J.; van Benthem, R.A.T.M.; de With, G. Surface Segregation of Low Surface Energy Polymeric Dangling Chains in a Cross-Linked Polymer Network Investigated by a Combined Experimental-Simulation Approach. Macromolecules 2013, 46, 1993-2002. [CrossRef]

66. Zhao, Z.; Li, X.; Li, P.; Wang, C.; Luo, Q. Study on properties of waterborne fluorinated polyurethane/acrylate hybrid emulsion and films. J. Polym. Res. 2014, 21, 460. [CrossRef]

67. Wayland, B.B.; Poszmik, G.; Mukerjee, S.L.; Fryd, M. Living radical polymerization of acrylates by organocobalt porphyrin complexes. J. Am. Chem. Soc. 1994, 116, 7943-7944. [CrossRef]

68. Hawker, C.J.; Bosman, A.W.; Harth, E. New polymer synthesis by nitroxide mediated living radical polymerizations. Chem. Rev. 2001, 101, 3661-3688. [CrossRef]

69. Kamigaito, M.; Ando, T.; Sawamoto, M. Metal-catalyzed living radical polymerization. Chem. Rev. 2001, 101, 3689-3746. [CrossRef]

70. Moad, G.; Rizzardo, E.; Thang, S.H. Living radical polymerization by the RAFT process-a second update. Aust. J. Chem. 2009, 62, 1402-1472. [CrossRef]

71. David, G.; Boyer, C.; Tonnar, J.; Ameduri, B.; Lacroix-Desmazes, P.; Boutevin, B. Use of Iodocompounds in Radical Polymerization. Chem. Rev. 2006, 106, 3936-3962. [CrossRef] [PubMed]

72. Boyer, C.; Ameduri, B.; Hung, M.H. Telechelic Diiodopoly(VDF-co-PMVE) Copolymers by Iodine Transfer Copolymerization of Vinylidene Fluoride (VDF) with Perfluoromethyl Vinyl Ether (PMVE)t. Macromolecules 2010, 43, 3652-3663. [CrossRef]

73. Sawada, H.; Tashima, T.; Nishiyama, Y.; Kikuchi, M.; Goto, Y.; Kostov, G.; Ameduri, B. Iodine Transfer Terpolymerization of Vinylidene Fluoride, $\alpha$-Trifluoromethacrylic Acid and Hexafluoropropylene for Exceptional Thermostable Fluoropolymers/Silica Nanocomposites. Macromolecules 2011, 44, 1114-1124. [CrossRef]

74. Kyulavska, M.; Kostov, G.; Ameduri, B.; Mateva, R. Unexpected alternating radical copolymerization of chlorotrifluoroethylene with 3-isopropenyl- $\alpha, \alpha^{\prime}$-dimethylbenzyl isocyanate. J. Polym. Sci. Part. A Polym. Chem. 2010, 48, 2681-2697. [CrossRef] 
75. Liu, L.; Lu, D.; Wang, H.; Dong, Q.; Wang, P.; Bai, R. Living/controlled free radical copolymerization of chlorotrifluoroethene and butyl vinyl ether under 60Co $\gamma$-ray irradiation in the presence of S-benzyl O-ethyl dithiocarbonate. Chem. Commun. 2011, 47, 7839-7841. [CrossRef] [PubMed]

76. Girard, E.; Marty, J.-D.; Ameduri, B.; Destarac, M. Direct Synthesis of Vinylidene Fluoride-Based Amphiphilic Diblock Copolymers by RAFT/MADIX Polymerization. ACS Macro Lett. 2012, 1, 270-274. [CrossRef]

77. Wang, P.; Dai, J.; Liu, L.; Jin, B.; Bai, R. Xanthate-mediated living/controlled radical copolymerization of hexafluoropropylene and butyl vinyl ether under 60Co $\gamma$-ray irradiation and preparation of fluorinated polymers end-capped with a fluoroalkyl sulfonic acid group. Polym. Chem. 2013, 4, 1760-1764. [CrossRef]

78. Wang, P.; Dai, J.; Liu, L.; Dong, Q.; Wang, H.; Bai, R. Synthesis and properties of a well-defined copolymer of chlorotrifluoroethylene and $\mathrm{N}$-vinylpyrrolidone by xanthate-mediated radical copolymerization under 60 Co $\gamma$-ray irradiation. Polym. Chem. 2014, 5, 6358-6364. [CrossRef]

79. Banerjee, S.; Ladmiral, V.; Debuigne, A.; Detrembleur, C.; Poli, R.; Ameduri, B. Organometallic-Mediated Radical Polymerization of Vinylidene Fluoride. Angew. Chem. Int. Ed. Engl. 2018, 57, 2934-2937. [CrossRef]

80. Kostov, G.; Boschet, F.; Buller, J.; Badache, L.; Brandsadter, S.; Ameduri, B. First amphiphilic poly (vinylidene fluoride-co-3, 3, 3-trifluoropropene)-b-oligo (vinyl alcohol) block copolymers as potential nonpersistent fluorosurfactants from radical polymerization controlled by xanthate. Macromolecules 2011, 44, 1841-1855. [CrossRef]

81. Guerre, M.; Uchiyama, M.; Lopez, G.; Améduri, B.; Satoh, K.; Kamigaito, M.; Ladmiral, V. Synthesis of PEVE-b-P(CTFE-alt-EVE) block copolymers by sequential cationic and radical RAFT polymerization. Polym. Chem. 2018, 9, 352-361. [CrossRef]

82. Pound, G.; McLeary, J.B.; McKenzie, J.M.; Lange, R.F.; Klumperman, B. In-situ NMR spectroscopy for probing the efficiency of RAFT/MADIX agents. Macromolecules 2006, 39, 7796-7797. [CrossRef]

83. Carnevale, D.; Wormald, P.; Ameduri, B.; Tayouo, R.; Ashbrook, S.E. Multinuclear Magnetic Resonance and DFT Studies of the Poly(chlorotrifluoroethylene-alt-ethyl vinyl ether) Copolymers. Macromolecules 2009, 42, 5652-5659. [CrossRef]

84. Lu, Y.; Claude, J.; Zhang, Q.; Wang, Q. Microstructures and Dielectric Properties of the Ferroelectric Fluoropolymers Synthesized via Reductive Dechlorination of Poly(vinylidene fluoride-co-chlorotrifluoroethylene)s. Macromolecules 2006, 39, 6962-6968. [CrossRef]

85. Tiers, G.V.D.; Bovey, F.A. Polymer NMR spectroscopy. VII. The stereochemical configuration of polytrifluorochloroethylene. J. Polym. Sci. Part. A General Papers 1963, 1, 833-841. [CrossRef] 